\title{
PSICANÁLISE E CLÍNICA AMPLIADA
}

\section{Maria Vitória Campos Mamede Maia}

Universidade Federal do Rio de Janeiro

\section{Perla Klautau}

Universidade Federal do Rio de Janeiro

\section{Rodrigo Peres Sanches}

Universidade Federal de Uberlândia

\section{Sílvia Nogueira Cordeiro}

Universidade Estadual de Londrina

O número suplementar de 2020 da revista Estudos Interdisciplinares em Psicologia reúne textos produzidos por membros do Grupo de Trabalho (GT) "Psicanálise e Clínica Ampliada", vinculado à Associação Nacional de Pesquisa e Pós-graduação em Psicologia (ANPEPP), com a colaboração de colegas externos ao GT.

Atualmente coordenado por Rodrigo Sanches Peres e Karla Patrícia Holanda Martins, este GT, desde sua formalização, vem discutindo a potência de práticas clínicas desenvolvidas em enquadres diversos (tradicionais e não tradicionais) com base na Psicanálise, bem como tem explorado a articulação dos saberes psicanalíticos a outros saberes que se debruçam sobre os processos de subjetivação atuais.

A editoração do presente número ficou sob a responsabilidade de Maria Vitória Campos Mamede Maia, Perla Klautau, Rodrigo Peres Sanches e Silvia Nogueira Cordeiro, sendo que foram seguidos os trâmites habituais da revista, com avaliação duplo-cego de todos os textos submetidos. Tal iniciativa resultou em uma edição composta por dez artigos.

O primeiro texto, de Érico Bruno Viana Campos, Lucianne Sant'Anna de Menezes e Josiane Cristina Bocchi, apresenta reflexões sobre o desamparo na constituição da subjetividade na atualidade e elege o sofrimento psíquico, o trabalho e a 
sublimação como eixos prioritários de investigação. No segundo artigo, "A escrita da história e do luto nas catástrofes coletivas", Karla Patrícia Holanda Martins e Fabiano Chagas Rabêlo exploram a pluralidade de sentidos do conceito de desmentido em Psicanálise, considerando as acepções de Freud e Ferenczi.

Já Maria Manuela Dias de Macedo e Perla Klautau examinam a função clínica do testemunho para a atuação de analistas em contextos de precarização, e discutem como a escuta psicanalítica pode operar como instrumento de cuidado. No quarto artigo, "Da solidão à capacidade de estar só na presença de alguém: percursos clínicos a partir da perspectiva de Winnicott", Nadja Nara Barbosa Pinheiro e Maria Vitória Campos Mamede Maia abordam teoricamente uma importante passagem no desenvolvimento emocional e veiculam duas ilustrações clínicas concernentes ao tema.

"A poética do luto: reflexão a partir do conceito de objeto transformacional", tematiza o potencial transformador dos encontros estéticos à luz das formulações de Bollas. Trata-se do quinto artigo, de Amanda Christina Victoria de Andrade Melani, Marina Ferreira da Rosa Ribeiro e Janderson Farias Silvestre dos Santos. O texto subsequente, assinado por Milton Bezerra de Lima e Véronique Donard, discorre sobre os efeitos da destituição discursiva em sujeitos que se encontram em situações extremas de sofrimento, além de que reflete sobre possibilidades quanto a práticas clínicas direcionadas aos mesmos.

No sétimo artigo, Rodrigo Sanches Peres e Josiane Cristina Bocchi discutem aportes psicanalíticos freudianos e pós-freudianos para a apreensão teórica da dor física e suas possíveis contribuições para a clínica ampliada. Em "A vida por um fio: a escuta clínica entre urgência subjetiva e urgência médica", Sílvia Nogueira Cordeiro e Fabiola da Silva Miranda relatam e problematizam um caso atendido em um serviço hospitalar por uma equipe multidisciplinar.

A seguir encontra-se o texto de Isabella Ferraz Lacerda Mello e Cassandra Pereira França, no qual são investigados os efeitos de uma verdade revelada aos filhos de um pedófilo que eram abusados sexualmente pelo próprio pai. Finalizando esse número, Vanessa Chreim e Elisa Maria de Ulhôa Cintra analisam as manifestações de um mecanismo de defesa presente em todas as formas de subjetivação, no artigo "A recusa e as crenças: a dimensão narcísica da não admissão da castração".

Desejamos a todos uma ótima leitura! 


\section{GERÊNCIA DE EDITORAÇÃO}

Dra. Maíra Bonafé Sei, Universidade Estadual de Londrina, Brasil

Dra. Patrícia Silva Lúcio, Universidade Estadual de Londrina, Brasil

\section{CONSELHO EDITORIAL}

Dra. Acácia Aparecida Angeli dos Santos, Universidade São Francisco, Brasil Dra. Alexandra Anache, Universidade Federal de Mato Grosso do Sul, Brasil Dra. Andrea Bustos Ibarra, Pontificia Universidad Católica de Valparaíso, Chile Dra. Evely Boruchovitch, Universidade Estadual de Campinas, Brasil Dr. Manoel Antônio dos Santos, Universidade de São Paulo, Brasil Dr. Roberto Calazans, Universidade Federal de São João del-Rey, Brasil Dr. Sebastián Urquijo, Universidad Nacional de Mar Del Plata, Argentina

\section{COMISSÃO EDITORIAL}

Deborah Klajnman, Universidade Estadual de Londrina, Brasil Maria Lúcia Ortolan, Universidade Estadual de Londrina, Brasil Nathália Tavares Bellato Spagiari, Universidade Estadual de Londrina, Brasil

\section{APOIO TÉCNICO}

Ana Carolina Moraes Silva, Universidade Estadual de Londrina, Brasil Eleonora Sonoda Gomes, Universidade Estadual de Londrina, Brasil

\section{REVISÃO DE LAYOUT}

Lérida de Oliveira 